\title{
REVIEW
}

\section{Role of emerging neuroimaging modalities in patients with cognitive impairment: a review from the Canadian Consensus Conference on the Diagnosis and Treatment of Dementia 2012}

\author{
Amer M Burhan*1, Robert Bartha², Christian Bocti ${ }^{3}$, Michael Borrie ${ }^{4}$, Robert Jr Laforce ${ }^{5}$, Pedro Rosa-Neto ${ }^{6}$
} and Jean-Paul Soucy

\begin{abstract}
The Fourth Canadian Consensus Conference on the Diagnosis and Treatment of Dementia (CCCDTD4) was held 3 to 4 May 2012 in Montreal, Quebec, Canada. A group of neuroimaging experts were assigned the task of reviewing and summarizing the literature on clinical and research applications of different neuroimaging modalities in cognitive disorders. This paper summarizes the literature and recommendations made to the conference regarding the role of several emerging neuroimaging modalities in cognitive disorders. Functional magnetic resonance imaging (MRI), magnetic resonance spectroscopy, and diffusion tensor imaging are discussed in detail within this paper. Other emergent neuroimaging modalities such as positron emission tomography with novel ligands, high-field MRI, arterial spin labeling MRI and noncerebral blood flow single-photon emission computerized tomography are only discussed briefly. Neuroimaging modalities that were recommended at the CCCDTD4 for both clinical and research applications such as amyloid and flurodeoxyglucose positron emission tomography, computerized tomography and structural MRI are discussed in a separate paper by the same authors. A literature search was conducted using the PubMed database including articles in English that involved human subjects and covered the period from the last CCCDTD publication (CCCDTD3; January 2006) until April 2012. Search terms included the name of the specific modality, dementia, Alzheimer's disease, and mild cognitive impairment. A separate search used the same parameters but was restricted to review articles to identify recent evidence-based reviews. Case studies and small case series were not included. Papers representing current evidence were selected, reviewed, and summarized, and the results were presented at the CCCDTD4 meeting with recommendations regarding the utility of various neuroimaging modalities in cognitive disorders. The evidence was graded according to the Oxford Centre for Evidence Based Medicine guidelines. Due to the limitations of current evidence, the neuroimaging modalities discussed in this paper were not recommended for clinical investigation of patients presenting with cognitive impairment. However, in the research setting, each modality provides a unique contribution to the understanding of basic mechanisms and neuropathological markers of cognitive disorders, to the identification of markers for early detection and for the risk of conversion to dementia in the at-risk populations, to the differentiation between different types of cognitive disorders, and to the identification of treatment targets and indicators of treatment response. In conclusion, for all of the neuroimaging modalities discussed in this paper, further studies are needed to establish diagnostic utility such as validity, reliability, and predictive and prognostic value. More multicenter studies are therefore needed with standardized image acquisition, experimental protocols, definition of the clinical population studied, larger numbers of participants, and longer duration of follow-up to allow generalizability of the results to the individual patient.
\end{abstract}

${ }^{*}$ Correspondence: Amer.burhan@sjhc.london.on.ca

'St Joseph's Health Care - London, University of Western Ontario, 850 Highbury

Street North, PO Box 5532, Station B, London, Ontario, Canada N6A 1 H4

Full list of author information is available at the end of the article 


\section{Introduction}

Neuroimaging plays a central role in the clinical research of cognitive disorders. A group of Canadian neuroimaging experts were asked to review and summarize the literature, and to provide recommendations regarding the clinical and research applications of different neuroimaging modalities in patients with cognitive impairment to the Fourth Canadian Consensus Conference on the Diagnosis and Treatment of Dementia (CCCDTD4) held 3 to 4 May 2012 in Montreal, Quebec. Other groups have published similar guidelines and recommendations, most recently the European Federation of Neurological Societies guidelines on the use of neuroimaging in the diagnosis of dementia [1].

The group built on other published guidelines, updated the evidence, and presented a rationale for the recommendations to CCCDTD4 in two papers. One paper by the same authors covered neuroimaging modalities currently indicated for clinical use in addition to research in cognitive disorders including $\left[{ }^{18} \mathrm{~F}\right]$ flurodeoxyglucose and $\left[{ }^{11} \mathrm{C}\right]$-labeled Pittsburgh compound-B amyloid positron emission tomography (PET), computerized tomography and structural magnetic resonance imaging (MRI). The current paper covers promising neuroimaging modalities that remain in the research realm but are not yet recommended for the clinical investigation of cognitive disorders.

For any medical test to have a diagnostic value in the individual patient, it must have established validity (having being tested across the spectrum of severity with appropriate randomization and compared with a golden diagnostic standard by an independent blinded rater), and to have established sensitivity, specificity, predictive value, and test-retest and inter-rater reliability (Appraisal of Diagnostic Test 2010 [2]). Most of these elements are still lacking for the neuroimaging modalities discussed in this paper. On the other hand, these modalities have important roles in addressing several research questions, such as: identification of the basic mechanisms of cognitive impairment and basic neuropathological markers of cognitive disorders; identification of markers for early detection and differentiation between normal aging, risk state, and dementia; identification of markers for differentiating between different types of cognitive disorders; understanding the neurobiological course of cognitive disorders (for example, changes in neuronal networks as a result of neurodegeneration and brain injury); identification of therapeutic targets and evaluation of the mechanism of action of different therapies in cognitive disorders; and enriching patient selection for therapeutic trials by identifying reliable neuropathological markers for different types of cognitive disorders.

There is significant variability in individuals presenting with cognitive disorders. The variability could be specific to the neuroimaging modality used but it could also be a general variability affecting most test results whether it is clinical, biological or from neuroimaging. In addition to the expected general variability (for example, demographic characteristics, stage of illness, and co-morbidity), there is emerging evidence regarding the impact of cognitive reserve on various test results. This effect was demonstrated in recent neuroimaging studies where regional cerebral blood flow measured by PET scanning was inversely related to the level of education and occupational attainment, indicating higher resiliency in those with higher cognitive reserve in the face of Alzheimer's pathology [3]. Issues related to sources of variability such as cognitive reserve have not been con $^{-}$ sidered adequately in neuroimaging studies at this stage.

The modalities discussed in greatest detail in this expert consensus review are: functional magnetic resonance imaging (fMRI), magnetic resonance spectroscopy (MRS), and diffusion tensor imaging (DTI). Other modalities such as PET imaging with novel ligands, arterial spinlabeling perfusion MRI, high-field MRI, and noncerebral blood flow single-photon emission computerized tomography (SPECT) are only discussed briefly due to the limited literature.

\section{Methodology}

A literature search of the PubMed database was performed and covered the period from the last CCCDTD publication (CCCDTD3; January 2006) until April 2012, so as not to duplicate the reviews already performed in the previous meetings $[4,5]$. Search terms included the name of the specific neuroimaging modality (fMRI, MRS, or DTI) combined with the terms 'dementia, 'Alzheimer's disease' (AD), or 'mild cognitive impairment' (MCI). The search was limited to 'English' and 'Humans'. A separate search used the same parameters but restricted it to review articles to identify recent evidence-based reviews. The purpose of this process was to summarize the evidence for the consensus meeting and make recommendations regarding the role of emerging neuroimaging modalities in cognitive disorders. This review was therefore focused and selective rather than a systematic review, and the search was not defined by statistical parameters but rather by a series of decisions by the authors to include or not include papers based on the pertinence of the information they contained. This approach resulted in some selected papers being included from the period preceding the interval mentioned above, if they were deemed necessary for a better understanding of the recommendations being made.

The evidence was summarized, and recommendations were submitted to the CCCDTD4 meeting for deliberation towards the goal of reaching a final expert consensus recommendation regarding the role of each selected 
emerging neuroimaging modality in cognitive disorders based on a majority vote on each of the recommendations by the attending members.

We graded the evidence based on the Oxford CEBM level of evidence grading guidelines (Levels of Evidence, March 2009 [2]). The evidence for the three main neuroimaging modalities discussed in this paper (fMRI, MRS and DTI) is mainly driven from well-designed casecontrolled studies with significant heterogeneity of participants and methodology. Therefore, the evidence for these modalities could be graded as $3 \mathrm{~b}$.

\section{Functional magnetic resonance imaging}

fMRI techniques identify brain activity level based on endogenous blood oxygen level-dependent (BOLD) image contrast. The BOLD signal is the product of the integrated synaptic activity of neurons and is mainly detected by MRI based on hemodynamic change in the oxyhemoglobin/deoxyhemoglobin ratio. An increased BOLD signal is usually interpreted as activation and a negative BOLD response as deactivation of the underlying brain areas [6].

There are mainly two types of fMRI studies used in cognitive disorders: those evaluating brain activation during episodic memory encoding and retrieval, and those evaluating the default mode network.

\section{Studies evaluating brain activation during episodic} memory encoding and retrieval in Alzheimer's disease and mild cognitive impairment patients

Typically fMRI experiments compare the MRI signal during one cognitive condition with a control condition such as visual fixation [7].

Episodic memory encoding function is most commonly investigated because of its early and consistent involvement in AD. Successful memory formation and retrieval requires coordinated and reciprocal activation of medial temporal lobe (MTL) structures and deactivation in areas connected to MTL areas such as the posterior cingulate cortex and parietal cortex [8].

During episodic memory encoding, AD patients consistently show lower activation in MTL structures, particularly the hippocampus [9-11], failure of the normal deactivation in posteromedial cortical areas such as the posterior cingulate and medial parietal cortex [12,13], and increased activation in the prefrontal cortex, probably as a compensation mechanism $[14,15]$. Similar pattern emerges during episodic memory retrieval (especially the lower activation of MTL).

In patients with $\mathrm{MCI}$, which is a risk state for $\mathrm{AD}$, the findings are mixed. During episodic memory encoding, some studies reported decreased activity $[9,16,17]$ while others reported increased activity in the MTL area. This discrepancy is probably due to several factors such as differences in clinical definition of $\mathrm{MCI}$, severity of cognitive impairment, and level of task performance [18].

Few fMRI studies followed MCI patients longitudinally. In one such study, baseline hyperactivation in MTL structures during episodic encoding correlated with future cognitive decline [19]. Another study showed that this activation declines over time, creating a U-curve pattern from hyperactivation to pseudo-normalization and finally to hypoactivation [20]. Table 1 summarizes the key findings of fMRI studies in AD and MCI patients during episodic memory encoding and retrieval based on published meta-analysis and evidence-based reviews [21-23].

\section{Studies evaluating the default mode network in Alzheimer's disease and mild cognitive impairment patients}

The brain network referred to as the default mode network includes several cortical areas that are particularly active at rest and deactivate during cognitive tasks. This network includes the medial prefrontal cortex, posterior cinculate cortex, precuneus, anterior cingulate cortex and parietal cortex. The hippocampus is functionally connected to this network. Recently, the correlation between the intrinsic oscillations or time courses of activity in the hippocampus and different brain regions of the default mode network in cognitive disorders has received significant attention [24]. This technique is feasible in patients with cognitive impairment because of the ease of acquisition and the lack of task performance confounding [25].

A significant alteration in the intrinsic functional connectivity between the hippocampus and areas in the default mode network at rest and during cognitive tasks in patients with MCI and AD has been reported [26-28]. Table 2 summarizes the findings of default mode network imaging studies in the resting state and deactivation during cognitive tasks based on a recent published review [29].

\section{Evaluation of the effect of pharmacological treatment using functional MRI}

Cholinergic therapy has been the mainstay for the treatment of cognitive disorders for over two decades. fMRI was used to evaluate the underlying mechanism of cholinergic therapy in healthy subjects and in patients with cognitive disorders. These studies evaluated the changes in the fMRI signal after a single dose and after short-term or long-term exposure to cholinergic agents. There is evidence for changes in the brain activation pattern in key memory, and especially attentional networks in response to cholinergic agents in healthy controls and in patients with $\mathrm{MCI}$ and $\mathrm{AD}$ during cognitive tasks. On the other hand, a significant variability in 
Table 1. Summary of functional magnetic resonance imaging study findings during episodic memory encoding and retrieval

\begin{tabular}{|c|c|c|}
\hline Cognitive task & Findings in Alzheimer's disease & Findings in $\mathrm{MCl}$ \\
\hline \multirow[t]{8}{*}{ Episodic memory encoding } & $\downarrow$ activation in MTL & \adaptive attenuation of hippocampus activation with \\
\hline & $\uparrow$ activation in right DLPFC, left VLPFC, left OFC, superior & \\
\hline & temporal gyri, fusiform gyri, and left thalamus & \multirow{2}{*}{$\begin{array}{l}\downarrow \text { activation in MTL structures and in bilateral frontal regions } \\
\text { in well-characterized amnestic } \mathrm{MCl}\end{array}$} \\
\hline & \multirow{5}{*}{$\begin{array}{l}\downarrow \text { activation cingulate, right mPFC, right insula, right } \\
\text { superior parietal lobule, and left precuneus }\end{array}$} & \\
\hline & & Delayed BOLD response \\
\hline & & $\begin{array}{l}\uparrow M T L \text { activation in early MCl patients who had comparable } \\
\text { task performance with controls, extent of MTL activity } \\
\text { positively correlated with successful encoding }\end{array}$ \\
\hline & & $\begin{array}{l}\text { Greater MTL functional MRI activation at baseline predicted } \\
\text { conversion to Alzheimer's disease }\end{array}$ \\
\hline & & $\begin{array}{l}\uparrow \text { activation in posterior hippocampus and parahippocampal } \\
\text { and fusiform regions, together with atrophy of more anterior } \\
\text { MTL }\end{array}$ \\
\hline \multirow[t]{3}{*}{ Episodic memory retrieval } & $\downarrow$ activation in MTL & $\downarrow$ activity in PCC \\
\hline & $\begin{array}{l}\uparrow \text { activation in right DLPFC and left VLPFC, left } \\
\text { supramarginal, and left precuneus, and right thalamus }\end{array}$ & \multirow[t]{2}{*}{$\downarrow$ activity in bilateral frontal regions and left hippocampus } \\
\hline & $\begin{array}{l}\downarrow \text { activation in left claustrum/amygdala, and bilateral } \\
\text { insula }\end{array}$ & \\
\hline
\end{tabular}

Summary of functional MRI study findings during episodic memory encoding and retrieval in Alzheimer's disease and MCI patients compared with healthy controls based on recent meta-analysis by Schwindt and colleagues [21] and reviews by Ries and colleagues [22] and Dickerson and Sperling [23]. BOLD, blood oxygen level dependent; DLPFC, dorsolateral prefrontal cortex; $\mathrm{MCl}$, mild cognitive impairment; $\mathrm{MPFC}$, medial prefrontal cortex; MRI, magnetic resonance imaging; MTL, medial temporal lobe; OFC, orbitofrontal cortex; PCC, posterior cingulate cortex; VLPFC, ventrolateral prefrontal cortex.

the results is observed - most probably due to heterogeneity of treatment response, variability in the pharmacokinetics and pharmacodynamics of these agents, and the inherent test-retest variability in fMRI studies [30]. More recently, a study by Li and colleagues demonstrated enhanced resting state functional connectivity and cerebral blood flow in patients with $\mathrm{AD}$ in response to long-term cholinergic treatment [31].

\section{Functional MRI in asymptomatic apolipoprotein E ع4 carriers}

fMRI studies in asymptomatic genetically at-risk subjects carrying apolipoprotein E $\varepsilon 4$ documented differences in BOLD signal during different cognitive tasks compared with noncarriers, although the direction of this difference and the factors affecting it are quite variable [32]. There are differences in resting state functional connectivity between apolipoprotein E $\varepsilon 2$ and $\varepsilon 4$ carriers on one end and apolipoprotein E $\varepsilon 3$ carriers on the other - the implications of this finding for cognitive disorders remains unclear [33]

Functional MRI in differentiating Alzheimer's disease from non-Alzheimer's disease dementia

Few fMRI studies compared AD with other forms of dementia. A differential pattern of resting state functional connectivity and task-induced BOLD signal has been identified between patients with $\mathrm{AD}$ patients compared with those with Lewy body dementia [34,35]. Other studies identified differential BOLD signal during cognitive tasks between AD patients and those with subcortical vascular cognitive impairment [36] and those with fronto-temporal dementia [37].

\section{Advantages and limitations of functional MRI in cognitive disorders}

There are several advantages for fMRI in cognitive disorders as a noninvasive and radioactivity-free modality allowing safe repeated scanning, with relatively high spatial and temporal resolution, and measurement of brain activity during specific behavior (like memory encoding).

On the other hand, fMRI is limited by sensitivity to head motion, effect of task performance, brain atrophy, and transient brain and body states at the time of scanning (for example, arousal, attention, and effort). fMRI is highly dependent on neurovascular coupling, resulting from neuronal and glia activity. This dependency makes fMRI especially vulnerable to the effect of conditions that affect vascular coupling, such as vascular insufficiency, change in blood gas levels, and exposure to substances. Furthermore, a change in activation in one area during a task might be related to a pathological change in other functionally connected areas [38]. Finally, test-retest reliability data for fMRI are just beginning to emerge in cognitive disorders [39]. 
Table 2. Key findings related to functional connectivity of default mode network or deactivation during cognitive tasks

\begin{tabular}{|c|c|c|}
\hline Condition & Findings in Alzheimer's disease & Findings in $\mathrm{MCl}$ \\
\hline \multirow[t]{8}{*}{$\begin{array}{l}\text { Functional connectivity of DMN } \\
\text { during resting state }\end{array}$} & $\begin{array}{l}\downarrow F C \text { between } \mathrm{HC} \text { and mPFC, PCC, precuneus and ventral } \\
\text { ACC }\end{array}$ & $\begin{array}{l}\downarrow F C \text { between PCC and ACC, PCC and frontal cortex, mPFC } \\
\text { and PCC, mPFC and ACC, mPFC and frontal cortex }\end{array}$ \\
\hline & \multirow{2}{*}{$\begin{array}{l}\downarrow \text { FC between PCC with mPFC, precuneus, and parietal } \\
\text { cortex }\end{array}$} & $\downarrow$ whole-brain FC to PCC and precuneus \\
\hline & & $\downarrow$ regional homogeneity in PCC and precuneus \\
\hline & $\uparrow F C$ between left $\mathrm{HC}$ and right IPFC & \multirow{5}{*}{$\begin{array}{l}\downarrow \text { amplitude of low-frequency fluctuations in mPFC, PCC, } \\
\text { precuneus and HC }\end{array}$} \\
\hline & $\uparrow F C$ between parietal and occipital cortex & \\
\hline & $\downarrow$ Connectivity and activity in $\mathrm{HC}$ and PCC & \\
\hline & $\downarrow$ in coherence in the PCC and precuneus & \\
\hline & $\uparrow$ local homogeneity in cuneus and left fusiform gyrus & \\
\hline \multirow{4}{*}{$\begin{array}{l}\text { Deactivation during cognitive } \\
\text { task }\end{array}$} & \multirow{2}{*}{$\begin{array}{l}\downarrow \text { deactivation in medial and lateral parietal regions during } \\
\text { associative memory paradigm }\end{array}$} & $\downarrow$ deactivation in PCC, precuneus and anterior frontal lobe \\
\hline & & Depends on severity with increased deactivation in mild $\mathrm{MCl}$ \\
\hline & $\begin{array}{l}\downarrow \text { deactivation in medial parietal and PCC during semantic } \\
\text { classification }\end{array}$ & \multirow[t]{2}{*}{$\begin{array}{l}\text { Cognitive reserve affects deactivation indicating } \\
\text { decompensation }\end{array}$} \\
\hline & $\begin{array}{l}\downarrow \text { in mPFC, PCC, precuneus, parietal cortex and HC during } \\
\text { nonspatial working memory and episodic visual memory } \\
\text { encoding }\end{array}$ & \\
\hline
\end{tabular}

Summary of the key findings related to functional connectivity of the DMN during the rest state or as evident by deactivation during cognitive tasks in patients with Alzheimer's disease and those with $\mathrm{MCl}$ compared with healthy controls [29]. DMN, default mode network; $\mathrm{FC}$, functional connectivity; $\mathrm{HC}$, hippocampus; $\mathrm{MCl}$, mild cognitive impairment; mPFC, medial prefrontal cortex; PCC, posterior cingulate cortex; ACC, anterior cingulate cortex; IPFC, left prefrontal cortex.

\section{Conclusion/recommendations}

Owing to several limitations, such as variability in imageacquisition protocols and experimental paradigms used, heterogeneity of the clinical population studied, limited data in other forms of dementia, small sample size, limited longitudinal data, limited test-retest reliability data, and inverted U-curve activation patter in the MTL in the people with MCI, fMRI is not currently recommended for the clinical investigation of patients presenting with cognitive impairment (level of evidence $3 \mathrm{~b}$ ).

On the other hand, fMRI holds promise in several areas such as early detection of dementia and predicting conversion of $\mathrm{MCI}$ to $\mathrm{AD}$, distinguishing between $\mathrm{AD}$ and non-AD dementia, identifying treatment target and changes in brain activation in response to intervention, and evaluating neuropsychiatric and behavioral symptoms in the context of preclinical and clinical dementia. Standardization of image-acquisition protocols and experimental paradigms and establishing validity and reliability data with large number of participants and longer follow-up periods are needed. Resting state methodology is a feasible and promising methodology and can be easily integrated into current large multicenter neuroimaging studies.

\section{['H]Magnetic resonance spectroscopy} ['H]Magnetic resonance spectroscopy in Alzheimer disease $\left[{ }^{1} \mathrm{H}\right] \mathrm{MRS}$ is a noninvasive technique used to measure the concentration of low molecular weight metabolites in vivo, with a detection threshold of approximately $1 \mathrm{mmol} / \mathrm{l}(1 \mathrm{mM})$. Although MRS data are acquired using a MRI scanner, the method is limited by a low signal to noise ratio resulting in volumes of interest typically ranging between 1 and $8 \mathrm{~cm}^{3}$. Data analysis also involves removal of line-shape distortions, removal of macromolecule/lipid contributions if needed, and fitting of the data to mathematical model functions to increase the accuracy of metabolite-level estimates [40]. The most commonly reported in vivo brain metabolites include $N$ acetylaspartate (NAA), glutamate, glutamine, cholinecontaining compounds (Cho), creatine $(\mathrm{Cr})$ compounds and myo-inositol. Altered levels of NAA or NAA/Cr are the most common finding reported in subjects with $\mathrm{AD}$ [41-49] and MCI, although alterations in other metabolites including myo-inositol [50], scyllo-inositol [51], and glutamate [52] have been reported. Decreased NAA has been documented in subjects with $\mathrm{AD}$ in the occipital lobe [53], temporal lobe [54], parietal lobe [55], and frontal lobe [56].

NAA is an amino acid located primarily within neurons in the central nervous system. The concentration of NAA is among the highest of the free amino acids in the brain ( 8 to $10 \mathrm{mM}$ in brain tissue) and it normally produces the largest peak in the magnetic resonance spectrum [57]. NAA is considered a marker of neuronal density and/or viability. Reduced NAA may therefore imply neuronal death, or it may indicate neurometabolic impairment based on the known correlation between the rate of mitochondrial activity and NAA synthesis [58]. NAA and myo-inositol change has been noted in the hippocampus in $\mathrm{AD}$, and this change has been associated with cognitive measures [59]. In fact, the NAA/myo-inositol ratio has 
been shown in several studies to be the most robust marker for discriminating $\mathrm{AD}$ patients from age-matched normal older controls [60,61]. NAA/myo-inositol ratios have also been previously shown to correlate with MiniMental State Examination scores [60]. Interested readers are directed to the review by Griffith and colleagues for a detailed description of MRS findings in the dementias [48].

\section{Longitudinal studies in subjects with mild cognitive impairment}

The value of MRS as a prognostic indicator of impending dementia in subjects with MCI can only be answered by longitudinal studies. Since 2005 there have been nine longitudinal MRS studies performed in subjects with MCI. Subjects were typically followed for 1 to 3 years to identify a cohort that converted to dementia. The results from these studies are summarized in Table 3.

The most consistent finding reported in MCI subjects that convert to dementia compared with MCI subjects that remain stable is lower NAA or NAA/Cr. Lower levels of NAA/Cr have been noted in several brain regions, including the occipital cortex [62], paratrigonal white matter [63], temporoparietal lobe [64], posterior cingulate [65,66], and posteriomedial cortex [67]. In the study by Rami and colleagues, lower NAA/Cr was observed in subjects that were classified as prodromal $\mathrm{AD}$ and later converted to AD [64]. Kantarci and colleagues demonstrated that $\mathrm{NAA} / \mathrm{Cr}$ measured from the posterior cingulate added predictive value for conversion to dementia when combined with hippocampal volume [66]. Furthermore, of these studies listed, three have included receiver operator curve analysis. Modrego and colleagues demonstrated that receiver operator curve analysis for $\mathrm{NAA} / \mathrm{Cr}<1.61$ predicted conversion with $100 \%$ sensitivity and $75 \%$ specificity [62]. The area under the curve was 0.91 with a positive predictive value of $83 \%$ and a negative predictive value of $100 \%$. Similarly, Fayed and colleagues showed that $\mathrm{NAA} / \mathrm{Cr}<1.40$ in the posterior cingulate predicted conversion of $\mathrm{MCI}$ to probable $\mathrm{AD}$ with sensitivity of $82 \%$ and specificity of $72 \%$ and an area under the curve of 0.82 [65]. Finally, Modrego and colleagues showed that NAA/Cr $<1.43$ in the posteromedial parietal cortex predicted conversion to probable AD with $74 \%$ sensitivity and $84 \%$ specificity and an area under the curve of 0.84 [67].

Despite the consistency of the studies listed above, two studies reported no baseline differences in $\left[{ }^{1} \mathrm{H}\right] \mathrm{MRS}$ between MCI stable patients and MCI converters in the bilateral posterior cingulate and inferior precuneus $[68,69]$ or in the parietal white matter [69]. Another study showed no differences in the medial temporal lobe in cognitively impaired not demented (CIND) stable patients and CIND converters in the medial temporal lobe [70].
Although current studies show an emerging trend of lower $\mathrm{NAA} / \mathrm{Cr}$ in $\mathrm{MCI}$ subjects that convert to dementia compared with MCI subjects that remain stable, further study is needed. Variability in participant selection, the criteria for conversion to dementia, and methodological inconsistencies in the brain region studied, the spectroscopy acquisition protocol, and the spectroscopy analysis procedures limits the generalizability of the current studies.

\section{Conclusion/recommendations}

MRS is not currently recommended for clinical investigation of patients presenting with cognitive impairment due to several limitations discussed above (level of evidence $3 b)$.

On the other hand, $\left[{ }^{1} \mathrm{H}\right] \mathrm{MRS}$ remains a promising technique as a research tool especially for the identification of subjects with MCI who will convert to dementia. Further multisite longitudinal studies should be conducted to establish normative values. Such studies should utilize standardized enrollment criteria, diagnosis criteria and data-acquisition methods, and include automated analysis of spectra that incorporates proper prior knowledge of metabolite line shapes. Future $\left[{ }^{1} \mathrm{H}\right]$ MRS studies to demonstrate clinical effectiveness should utilize $3 \mathrm{~T}$ MRI where available to increase data quality.

\section{Diffusion tensor imaging}

Volumetric MRI measures of the MTL or hippocampus have been validated as markers of neuronal damage and can support the diagnosis of early AD [71]. As gray matter atrophy is presumably a relatively downstream event, efforts to detect earlier changes at the microstructural level are worth pursuing as part of the general effort to define the earliest measurable changes that lead to $\mathrm{AD}$.

Diffusion-weighted imaging has been used clinically over the past 10 to 20 years, mainly to detect acute stroke. This imaging modality can provide a window into the structural integrity of cerebral tissue beyond what is visible on standard MRI. Molecular diffusion refers to the random movements of molecules, which can be described statistically given the size of the molecule and the temperature and nature of the medium through which it travels [72]. In pure water, molecules move in all directions with equal probability (isotropy). Diffusionweighted imaging uses information derived from the random movements of water molecules through biological tissues; white matter tracts with their neuronal membranes and myelin sheaths interfere with the random movements of water molecules, thus rendering the movements an-isotropic. The main measures obtained are mean diffusivity (MD) and fractional anisotropy (FA). These measures provide indirect information on the 
Table 3. Summary of ['H]magnetic resonance spectroscopy longitudinal studies

\begin{tabular}{|c|c|c|c|c|c|c|c|c|}
\hline Authors & Year & Patients & $\begin{array}{l}\text { Follow-up } \\
\text { (months) }\end{array}$ & $\begin{array}{l}\text { Converted } \\
\text { to } A D\end{array}$ & MRI & $\begin{array}{l}\text { Voxel size } \\
\left(\mathrm{cm}^{3}\right)\end{array}$ & Brain region & Results \\
\hline $\begin{array}{l}\text { Chao and } \\
\text { colleagues } \\
{[70]}\end{array}$ & 2005 & 17 CIND & 43 & 6 & $\begin{array}{l}1.5 \mathrm{~T}, \\
\text { Siemens }\end{array}$ & 0.9 & $\begin{array}{l}\text { Medial temporal } \\
\text { lobe }\end{array}$ & $\begin{array}{l}\text { CIND converters had less medial temporal } \\
\text { lobe NAA than controls. No difference } \\
\text { between CIND stable and controls. No } \\
\text { significant difference between CIND } \\
\text { converters and CIND stable }\end{array}$ \\
\hline
\end{tabular}

\begin{tabular}{|c|c|c|c|c|c|c|c|}
\hline $\begin{array}{l}\text { Modrego and } \\
\text { colleagues } \\
{[62]}\end{array}$ & 2005 & $55 \mathrm{MCl}$ & 29 & 1.5 T, GE & 8 & $\begin{array}{l}\text { Left } \\
\text { hippocampus, } \\
\text { right parietal } \\
\text { cortex, left } \\
\text { occipital cortex }\end{array}$ & $\begin{array}{l}\text { Occipital cortex NAA/Cr predicted } \\
\text { conversion to dementia. ROC analysis for } \\
\text { NAA }<1.61 \text { predicted conversion with } \\
100 \% \text { sensitivity and } 75 \% \text { specificity. Area } \\
\text { under the curve was } 0.91 \text { with positive } \\
\text { predictive value of } 83 \% \text { and a negative } \\
\text { predictive value of } 100 \%\end{array}$ \\
\hline
\end{tabular}

\begin{tabular}{|c|c|c|c|c|c|c|c|c|}
\hline $\begin{array}{l}\text { Metastasio } \\
\text { and } \\
\text { colleagues } \\
\text { [63] }\end{array}$ & 2006 & $25 \mathrm{MCl}$ & 12 & 5 & 1.5 T, GE & 8 & $\begin{array}{l}\text { Left and right } \\
\text { paratrigonal } \\
\text { white matter }\end{array}$ & $\begin{array}{l}\text { Lower NAA/Cr at baseline for } \mathrm{MCl} \\
\text { converters compared with } \mathrm{MCl} \text { stable }\end{array}$ \\
\hline $\begin{array}{l}\text { Rami and } \\
\text { colleagues } \\
\text { [64] }\end{array}$ & 2007 & $\begin{array}{l}14 \mathrm{MCl}, 28 \\
\text { prodromal } \\
\mathrm{AD}\end{array}$ & 12 & $\begin{array}{l}3 \mathrm{MCl}, 16 \\
\text { prodromal } \\
\mathrm{AD}\end{array}$ & 1.5 T, GE & 8 & $\begin{array}{l}\text { Posterior } \\
\text { cingulate, } \\
\text { left temporal } \\
\text { pole, left } \\
\text { temporoparietal } \\
\text { cortex }\end{array}$ & $\begin{array}{l}\text { Posterior cingulate had higher } \mathrm{Cho} / \mathrm{Cr} \text { at } \\
\text { baseline in } \mathrm{MCl} \text { converters compared with } \\
\mathrm{MCl} \text { stable. Temperoparietal lobe showed } \\
\text { lower } \mathrm{NAA} \text {, Cho, and } \mathrm{Cr} \text { at baseline in } \\
\text { prodromal } \mathrm{AD} \text { converters compared with } \\
\text { nonconverters }\end{array}$ \\
\hline $\begin{array}{l}\text { Kantarci and } \\
\text { colleagues } \\
\text { [68] }\end{array}$ & 2007 & $49 \mathrm{MCl}$ & 13 & 18 & 1.5 T, GE & 8 & $\begin{array}{l}\text { Bilateral } \\
\text { posterior } \\
\text { cingulate } \\
\text { and inferior } \\
\text { precuneus }\end{array}$ & $\begin{array}{l}\text { No baseline }{ }^{1} \mathrm{H} \text { MRS differences between } \\
\mathrm{MCl} \text { stable and } \mathrm{MCl} \text { converters }\end{array}$ \\
\hline $\begin{array}{l}\text { Feyed and } \\
\text { colleagues } \\
\text { [65] }\end{array}$ & 2008 & $119 \mathrm{MCl}$ & 29 & 54 & 1.5 T, GE & 8 & $\begin{array}{l}\text { Bilateral } \\
\text { posterior } \\
\text { cingulate, left } \\
\text { occipital cortex }\end{array}$ & $\begin{array}{l}\mathrm{NAA} / \mathrm{Cr}<1.40 \text { in posterior cingulate } \\
\text { predicted conversion of } \mathrm{MCl} \text { to probable } \\
\mathrm{AD} \text { with a sensitivity of } 82 \% \text { and specificity } \\
\text { of } 72 \% \text {. Area under the curve was } 0.82\end{array}$ \\
\hline $\begin{array}{l}\text { Pilatus and } \\
\text { colleagues } \\
\text { [69] }\end{array}$ & 2009 & $15 \mathrm{MCl}$ & 42 & 6 & $\begin{array}{l}1.5 \mathrm{~T}, \\
\text { Philips }\end{array}$ & 8 & $\begin{array}{l}\text { Posterior } \\
\text { cingulate, } \\
\text { parietal white } \\
\text { matter }\end{array}$ & $\begin{array}{l}\text { Did not replicate predictive power of NAA } \\
\text { at baseline }\end{array}$ \\
\hline $\begin{array}{l}\text { Kantarci and } \\
\text { colleagues } \\
{[66]}\end{array}$ & 2009 & $151 \mathrm{MCl}$ & $\begin{array}{l}12 \text { month } \\
\text { evaluation }\end{array}$ & 75 & 1.5 T, GE & 8 & $\begin{array}{l}\text { Bilateral } \\
\text { posterior } \\
\text { cingulate } \\
\text { and inferior } \\
\text { precuneus }\end{array}$ & $\begin{array}{l}\text { Multivariate analysis showed that NAA } \\
\text { Cr added predictive value in addition to } \\
\text { hippocampal volume and the presence of } \\
\text { cortical infarction }\end{array}$ \\
\hline $\begin{array}{l}\text { Modrego and } \\
\text { colleagues } \\
{[67]}\end{array}$ & 2011 & $71 \mathrm{MCl}$ & 22 & 27 & 1.5 T, GE & 8 & $\begin{array}{l}\text { Bilateral } \\
\text { posteromedial } \\
\text { cortex, left } \\
\text { medial occipital } \\
\text { lobe }\end{array}$ & $\begin{array}{l}\text { Decreased NAA/Cr in converters compared } \\
\text { with nonconverters in posteromedial } \\
\text { cortex and occipital lobe. NAA/Cr ratio } \\
\leq 1.43 \text { in posteromedial parietal cortex } \\
\text { predicted conversion to probable AD at } \\
74.1 \% \text { sensitivity and } 83.7 \% \text { specificity; area } \\
\text { under curve was } 0.84 \text {. In left occipital lobe, } \\
85.2 \% \text { sensitivity, } 61.4 \% \text { specificity; area } \\
\text { under the curve of } 0.8\end{array}$ \\
\hline
\end{tabular}

Since 2005, there have been nine longitudinal MRS studies performed in subjects with cognitive impairment. Subjects were typically followed for 1 to 3 years to identify a cohort that converted to dementia. AD, Alzheimer's disease; Cho, choline containing compounds; CIND, cognitively impaired not demented; $C r$, creatine; GE, GE Healthcare (Waukesha, WI, USA); MCl, mild cognitive impairment; MRI, magnetic resonance imaging; MRS, magnetic resonance spectroscopy; NAA, $\mathrm{N}$-acetylaspartate; Philips, Philips Medical Solutions (Best, The Netherlands); Siemens, Siemens Medical Solutions (Erlangen, Germany). 
microscopic structural properties of white matter fibers [73].

With recent advances in diffusion data modeling, it is now possible to determine in vivo the location of white matter nerve bundles using algorithms that estimate the likelihood that two adjacent voxels are connected (DTI tractography). This type of analysis can provide exquisite detail of the white matter tracts that connect different areas of the brain, including the large-scale neural networks that underlie all cognitive functions [74]. Analysis of DTI data becomes more complex at fiber intersections, and estimates of white matter voxels containing crossing fibers range from 63 to $90 \%$ depending on the estimation method used [75]. This implies that most first-generation DTI studies are limited in their power in at least two-thirds of the voxels, enabling clear visualization of only the most prominent white matter tracts such as the cortico-spinal tract. With the emergence of new high angular resolution diffusion imaging methods, it has been possible to manage the problem of crossing fibers and the complex configurations of bundles of white matter [76,77], enabling much more detailed visualization of smaller white fiber bundles. These tools are well suited to study large-scale brain anatomical connectivity and are particularly well suited for the study of complex brain disorders such as AD.

Several studies in the past decade have focused on the value of DTI measures in the differentiation of MCI and $\mathrm{AD}$ from controls; 55 studies comprising close to 2,800 subjects were included in a recent meta-analysis. This analysis compared the contribution of FA and MD to the better established imaging measures of MTL atrophy in the diagnosis of $\mathrm{MCI}$ and $\mathrm{AD}$ using the magnitude of effect sizes as the method of comparison. Studies using FA measures at the level of regions of interests showed significant differences between $\mathrm{AD}$ and controls, with the largest effect sizes in the cingulum, splenium of the corpus callosum, uncinate fasciculus, superior longitudinal fasciculus and frontal lobes. For studies using MD, the regions of interest most useful to distinguish $\mathrm{AD}$ from controls were the hippocampus, splenium of the corpus callosum, parietal lobes and temporal lobes. In general, effect sizes were superior for the volumetric MTL measures compared with the DTI measures for the discrimination between controls and $\mathrm{AD}$ subjects. Predictably, the differences between MCI and controls were of less magnitude, with only regions of the cingulum showing moderate effect sizes using FA. However, in the comparison between MCI and controls, studies using hippocampal MD showed superior effect sizes compared with volumetric MTL measures [78].

Another recent review, using pooled analysis of regional mean FA and MD values, showed that MD values are different in all white matter regions of the brain between controls and AD subjects, and that FA showed similar results except for the parietal lobe and internal capsule [79]. Furthermore, a few studies in healthy older subjects at risk for $\mathrm{AD}$ showed abnormalities in $\mathrm{MD}$ values in regions known to be affected in $\mathrm{AD}[80,81]$. In addition to showing early alterations in MCI patients, DTI appears to correlate with cognitive performance independent of cortical atrophy, which suggests access to an upstream process in the neurodegenerative cascade [82].

The search for appropriate DTI and high angular resolution diffusion imaging parameters for the diagnosis of cognitive impairment is still a work in progress [83]. Various parameters behave in different ways according to localization [84]. In addition to the choice of diffusion parameters, recent tractography studies illustrate the superiority of analysis methods that can manage crossing fibers $[85,86]$. The analysis of large-scale networks involved in cognitive functions might enable more specific correlations between brain structure and function [87]. Table 4 summarizes DTI findings in AD and MCI based on the two recently published meta-analyses [78,79].

\section{Conclusion/recommendations}

The DTI technique shows promise as a potential imaging biomarker in the early diagnosis of high-risk states for $\mathrm{AD}$, and has similar accuracy to volumetric hippocampal measures for the diagnosis of established AD. However, due to significant heterogeneity in studies in terms of patient characteristics and image-acquisition parameters, DTI is not currently recommended for the clinical investigation of patients presenting with cognitive impairment (level of evidence 3b).

Potential clinical applications of tractography include support for the diagnosis of neurodegenerative diseases [88], but also identification of amnestic MCI $[82,89]$ and prediction of progress to AD in risk groups $[90,91]$. Further studies with standardized image-acquisition and analysis protocols, a standardized definition of participants, a larger number of participants across age and gender distributions, and a longer follow-up period will increase validity and reliability of the data and allow better generalization of results to the individual patient.

\section{Other emerging neuroimaging modalities used in the evaluation of cognitive disorders}

In this section we briefly discuss neuroimaging modalities that hold promise as research tools in cognitive disorders but have less published literature, which limits conclusions and recommendations at this time.

\section{Scanning with emerging PET ligands}

PET imaging offers a variety of techniques that have a significant role in investigating patients with cognitive impairment. Amyloid imaging with $\left[{ }^{11} \mathrm{C}\right]$-labeled Pittsburgh 
Table 4. Summary of brain regions showing statistically significant differences

\begin{tabular}{|c|c|c|c|c|c|c|}
\hline \multirow[b]{2}{*}{ Measure } & \multicolumn{2}{|c|}{ AD vs. NC (NC vs. AD) } & \multicolumn{2}{|c|}{ MCl vs. NC (NC vs. MCl) } & \multicolumn{2}{|c|}{$\mathrm{MCl}$ vs. AD } \\
\hline & Region & Effect size & Region & Effect size & Region & Effect size \\
\hline \multirow[t]{8}{*}{ Fractional anisotropy ${ }^{a}$} & Frontal lobes & $-0.64(0.70)$ & Frontal & -0.51 (NS) & Frontal & 0.29 \\
\hline & Temporal & $-0.74(0.57)$ & Temporal & $-0.46(0.38)$ & Temporal & 0.27 \\
\hline & parahippocampal & $-0.67(1.17)$ & Hippocampus (PHg) & $-0.97(0.97)$ & $\mathrm{PCg}$ & 0.37 \\
\hline & PCg & $-0.86(0.84)$ & $\mathrm{PCg}$ & $-0.53(0.65)$ & Genu & 0.35 \\
\hline & Genu & $-0.51(0.63)$ & Genu & $-0.42(0.41)$ & Splenium & 0.51 \\
\hline & Splenium & $-0.70(1.10)$ & Splenium & $-0.60(0.44)$ & & \\
\hline & UF & $-1.14(1.03)$ & SLF & -0.77 (NS) & & \\
\hline & SLF & $-0.85(0.77)$ & & & & \\
\hline \multirow[t]{9}{*}{ Mean diffusivity ${ }^{b}$} & Frontal & $0.50(-0.75)$ & Temporal & $0.55(-0.40)$ & $\mathrm{PCg}$ & -0.40 \\
\hline & Temporal & $0.73(-0.89)$ & Parietal & $0.86(-0.69)$ & Genu & -0.32 \\
\hline & Parietal & $0.72(-1.03)$ & Genu & $0.43(-0.43)$ & Splenium & -0.04 \\
\hline & Occipital & $0.47(-0.67)$ & Splenium & $0.63(-0.46)$ & & \\
\hline & Hippocampus & $0.60(-1.17)$ & PCg & $0.32(-0.26)$ & & \\
\hline & PCg & $0.69(-0.74)$ & Hippocampus & $1.08(-1.0)$ & & \\
\hline & Genu & $0.50(-0.67)$ & & & & \\
\hline & Splenium & $0.56(-0.94)$ & & & & \\
\hline & UF & $0.66(-0.72)$ & & & & \\
\hline
\end{tabular}

Effect sizes are summarized per region [78,79]. AD, Alzheimer's disease; $\mathrm{MCl}$, mild cognitive impairment; $\mathrm{NC}$, normal controls; $\mathrm{PCg}$, posterior cingulate gyrus; $\mathrm{PHg}$

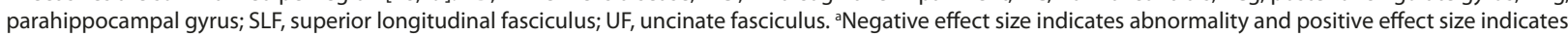
integrity of white matter. ${ }^{b}$ Positive effect size indicates abnormality and negative effect size indicates integrity of white matter.

compound-B amyloid and $\left[{ }^{18} \mathrm{~F}\right]$ flurodeoxyglucose PET are covered elsewhere.

Several novel amyloid ligands are being developed to enhance sensitivity and specificity of PET amyloid imaging and to increase feasibility of scanning by having a longer half-life (see Figure 1 for an example of amyloid binding with the novel ligand $\left[{ }^{18} \mathrm{~F}\right]$ florbetapir). Amyloidbinding SPECT agents are being considered, which will offer another feasible method of imaging amyloid [92].

A molecular probe with high affinity to tubulin associated unit (TAU) fibrils and a low affinity for synthetic amyloid- $\beta_{1-42}$ fibrils is in the early phase of development [93].

There is evidence for regional neurotransmitter alteration in AD. Imaging the dopamine system with PET tracers can help to differentiate $\mathrm{AD}$ from Lewy Body Dementia (LBD) and LBD from Parkinson's disease. Several PET ligands are available to image the serotonin system; for example, 5- $\mathrm{HT}_{1 \mathrm{~A}}$ imaging can reveal hippocampal neurodegeneration in $\mathrm{AD}$, and reduction in $5-\mathrm{HT}_{2 \mathrm{~A}}$ binding has been demonstrated in $\mathrm{AD}$ and in MCI patients.

Imaging the cholinergic system offers better understanding of the basic mechanism of cognitive symptoms and response to cholinergic therapies in AD, Parkinson's disease dementia, LBD and other dementia. Cholinergic nicotinic declines have been measured with PET nicotine receptor ligands. Reduced acetyl cholinesterase activity has been shown in MCI converters, AD, LBD and Parkinson's disease dementia compared with healthy controls, and basal acetyl cholinesterase activity predicts therapeutic effects of cholinesterase inhibitors.

Neuroinflammation is a neuropathological feature of numerous neurodegenerative conditions. PET allows for in vivo quantification of various aspects of neuroinflammatory responses, which may serve to monitor the effects of pharmacological interventions. Using PET ligands, high phospholipase enzymatic and high astrocytic activity has been described in the AD brain [94,95]. Finally, microglial activation detected via specific PET ligand binding has been described in several neurodegenerative conditions. Biomarkers of tissue pathology have potential applications for monitoring disease progression and evaluating the effects of new pharmacological interventions, accumulation abnormal proteins in the brain, neurodegeneration, neuroinflammation and neurotransmission. Table 5 presents common PET ligands used to delineate different neurobiological processes in cognitive disorders. Interested readers are referred to recent published reviews for more details [96,97].

\section{Arterial spin labeling perfusion magnetic resonance imaging} In this technique, the water content in arterial blood is labeled to detect change in perfusion. This method is 


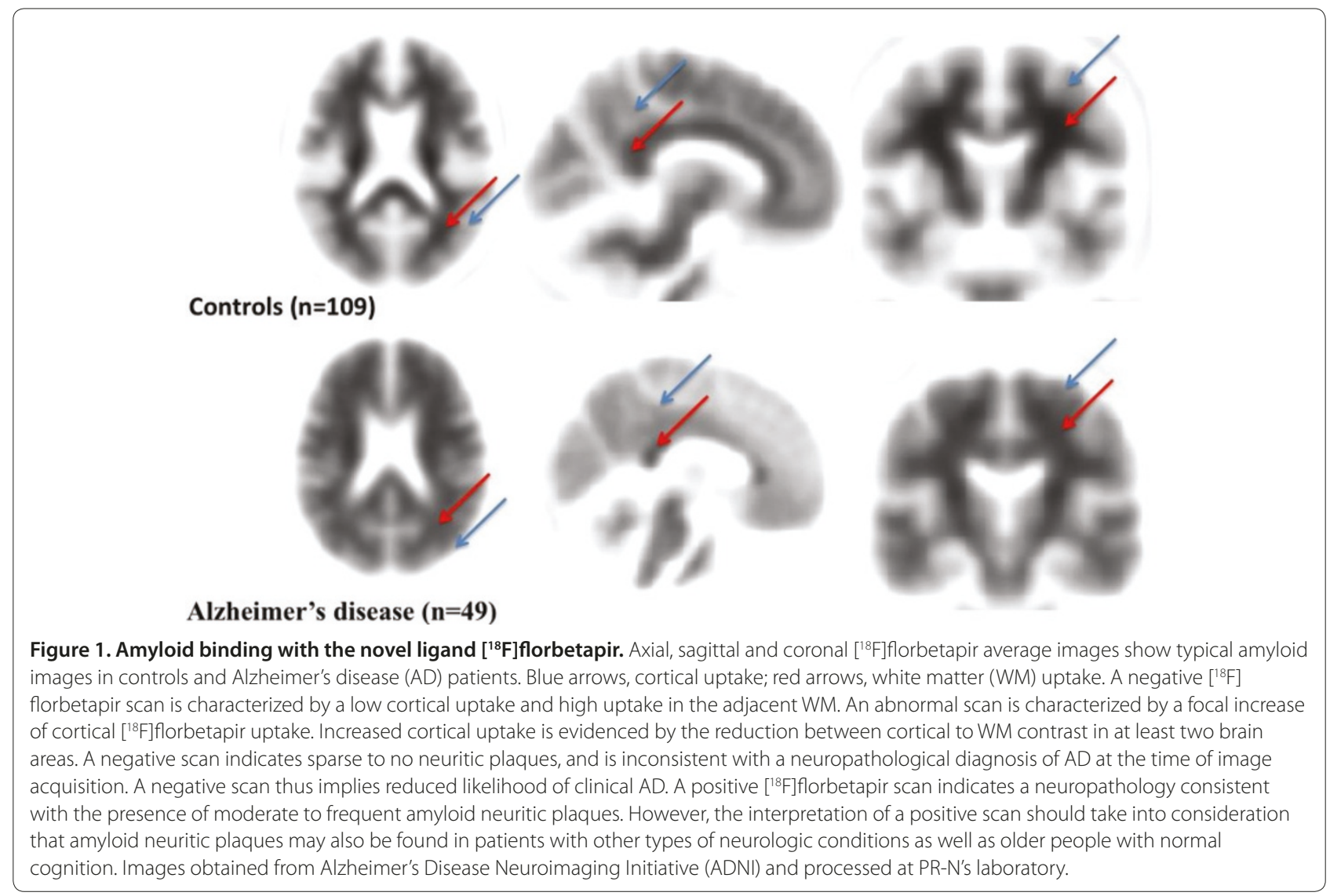

similar to $\left[{ }^{18} \mathrm{~F}\right]$ flurodeoxyglucose PET as it detects perfusion change but with no exposure to radioactivity. Recent studies using this method have shown hypoperfusion in some brain areas in MCI and AD patients compared with controls, including the right inferior parietal, bilateral posterior cingulate gyri, and bilateral middle frontal gyri, a pattern of hypoperfusion that is similar the one seen with PET and SPECT scan studies in this population $[98,99]$.

\section{Noncerebral blood flow-based single-photon emission computerized tomography}

Noncerebral blood flow studies can be performed to differentiate LBD from AD with SPECT agents targeting the dopamine cell membrane transporter. [ $\left.{ }^{123} \mathrm{I}\right]$-labeled ioflupane is useful in differentiating Lewy body dementia from AD with high specificity over 90\% [100].

Another noncerebral blood flow SPECT approach is based on imaging of the norepinephrine transporter on the plasma membrane of sympathic terminals in the heart, which are lost early in LBD and Parkinson's disease, but not in AD using the ligand iodine-131 metaiodobenzylguanidine. This tracer is approved for human use mostly for the diagnosis and treatment of paragangliomas. Results in small studies have demonstrated above $90 \%$ accuracy for the diagnosis of LBD $[101,102]$.

\section{Ultra-high-field magnetic resonance imaging}

The use of ultra-high-field ( $>3 \mathrm{~T}$ ) human MRI has increased over the past two decades. The advantages of ultra-high-field MRI include greater signal to noise ratio, reduced scan times, increased image resolution, increased spectral dispersion, and novel contrast. However, there are technical and logistic challenges including increased magnetic field distortions, decreased radiofrequency field homogeneity, increased power deposition, and the unknown safety profile of most surgical implants at field strengths above $3 \mathrm{~T}$. These issues need to be addressed but initial studies have demonstrated the advantages of this technology for the study of the human brain, and AD in particular [103-105].

\section{Discussion}

In this expert consensus review, we summarize the literature regarding emerging neuroimaging modalities used to study patients with cognitive impairment that are not currently recommended for the clinical investigation 
Table 5. Novel positron emission tomography ligands commonly used in studying cognitive disorders

\begin{tabular}{|c|c|}
\hline Target & Ligands \\
\hline \multirow[t]{6}{*}{ Amyloid (novel ligands) } & {$\left[{ }^{11} \mathrm{C}\right] 6-\mathrm{OH}-\mathrm{BTA}-1$, Pittsburgh compound $\mathrm{B}$} \\
\hline & {$\left[{ }^{11} \mathrm{C}\right] A Z D 2184$} \\
\hline & {$\left[{ }^{11} \mathrm{C}\right] \mathrm{BF}-227$} \\
\hline & {$\left[{ }^{18} \mathrm{~F}\right]$ Flutemetamol } \\
\hline & {$\left[{ }^{18} \mathrm{~F}\right] \mathrm{BAY} 94-9172$, florbetaben } \\
\hline & {$\left[{ }^{18} \mathrm{~F}\right] \mathrm{AV}-45$, florbetapir } \\
\hline Tubulin associated unit & {$\left[{ }^{18} \mathrm{~F}\right] \mathrm{THK} 523$} \\
\hline \multicolumn{2}{|l|}{ Neurotransmitters } \\
\hline \multirow[t]{4}{*}{ Dopamine } & $\begin{array}{l}{\left[{ }^{18} \mathrm{~F}\right] \mathrm{Flurodopa} \text { : dopa decarboxylation and }} \\
\text { vesicular storage }\end{array}$ \\
\hline & {$\left[{ }^{18} \mathrm{~F} /{ }^{11} \mathrm{C}\right] \mathrm{FP}-\mathrm{ClT}$ and related: dopa transporter } \\
\hline & $\begin{array}{l}{\left[{ }^{11} C\right] \text { Raclopride: } \mathrm{D} 2 \text { receptor binding in basal }} \\
\text { ganglia }\end{array}$ \\
\hline & $\begin{array}{l}{\left[{ }^{[8} \mathrm{F}\right] \text { Fallypride: } \mathrm{D} 2 \text { receptor binding in the }} \\
\text { cortex }\end{array}$ \\
\hline \multirow[t]{3}{*}{ Serotonin } & {$\left[{ }^{11} \mathrm{C}\right] \mathrm{DASB}$ and related: serotonin transporter } \\
\hline & $\begin{array}{l}{\left[{ }^{[1} \mathrm{C}\right] \text { WAY-100635 and }\left[{ }^{18} \mathrm{~F}\right] \mathrm{MPPF}: 5-\mathrm{HT} \mathrm{1A}_{1 \mathrm{~A}}} \\
\text { receptors }\end{array}$ \\
\hline & $\begin{array}{l}{\left[{ }^{18} \mathrm{~F} /{ }^{11} \mathrm{C}\right] \text { Altanserin, }\left[{ }^{11} \mathrm{C}\right] \mathrm{MDL}-100907: 5-\mathrm{HT}_{2 \mathrm{~A}}} \\
\text { receptors }\end{array}$ \\
\hline \multirow[t]{3}{*}{ Cholinergic } & $\begin{array}{l}{\left[{ }^{11} \mathrm{C}\right] \mathrm{MP} 4 \mathrm{~A} \text { and related: acetyl choline esterase }} \\
\text { activity }\end{array}$ \\
\hline & {$\left[{ }^{11} \mathrm{C}\right]$ Nicotine, $\left[{ }^{[8} \mathrm{F}\right] \mathrm{A} 85380$ : nicotine receptors } \\
\hline & $\begin{array}{l}{\left[{ }^{11} \mathrm{C}\right] \mathrm{NMPB},\left[{ }^{18} \mathrm{~F}\right] \mathrm{FP}-\mathrm{TZTP} \text { : muscarinergic }} \\
\text { receptors }\end{array}$ \\
\hline \multirow[t]{2}{*}{ Neuroinflammation } & $\begin{array}{l}{\left[{ }^{11} C\right] \text { Arachidonic acid: phospholipase }} \\
\text { enzymatic activity }\end{array}$ \\
\hline & $\begin{array}{l}{\left[{ }^{11} C\right] \text { Deprenyl: astrocytic activity irreversibly }} \\
\text { binds to the astrocytic enzyme monoamine } \\
\text { oxidase B }\end{array}$ \\
\hline \multirow[t]{3}{*}{ Microglia activation } & {$\left[{ }^{11} \mathrm{C}\right] \mathrm{PK}-11195$} \\
\hline & {$\left[{ }^{11} \mathrm{C}\right] \mathrm{DAA} 1106$} \\
\hline & {$\left[{ }^{11} \mathrm{C}\right]$ Vinpocetine } \\
\hline
\end{tabular}

of this population. These modalities have a role in identifying indicators of neuropathology, which has the potential to inform research by providing better markers for inclusion/exclusion in clinical and research protocols in the future. For these neuroimaging modalities to have diagnostic value in the individual patient, they must have established validity and to have established sensitivity, specificity, predictive value, and test-retest and interrater reliability. Most of these elements are still lacking for the modalities discussed in this paper.

International multicenter neuroimaging initiatives are well underway and provide the opportunity for multimodal standardized protocols allowing combining neuroimaging modalities together with clinical and other biological markers (for example, genetics and cerebrospinal fluid) [106]. Some of the neuroimaging modalities discussed in this paper - such as DTI, resting-state fMRI, and MRS - are quite feasible to acquire during MRI studies. Furthermore, post-acquisition processing and analysis is getting more accessible with the advances in image processing and analysis software. Larger longitudinal studies with improved homogeneity of participants and methods, combining neuroimaging and other diagnostic data, will probably give modalities discussed in this paper clinical utility in the near future.

\section{Conclusion}

For neuroimaging modalities discussed in this paper, further studies are needed to establish diagnostic utility. Larger, multicenter, multimodal studies with better homogeneity of the clinical population and methodology are therefore needed to establish diagnostic value for the individual patient.

\begin{abstract}
Abbreviations
AD, Alzheimer's disease; BOLD, blood oxygen level dependent; CCCDTD4, Fourth Canadian Consensus Conference on the Diagnosis and Treatment of Dementia; CIND, cognitively impaired not demented; Cr, creatine; DTI, diffusion tensor imaging; FA, fractional anisotropy; fMRI, functional magnetic resonance imaging; LBD, Lewy Body Dementia; $\mathrm{MCl}$, mild cognitive impairment; $M D$, mean diffusivity; MRI, magnetic resonance imaging; MRS, magnetic resonance spectroscopy; MTL, medial temporal lobe; NAA, $\mathrm{N}$-acetylaspartate; PET, positron emission tomography; SPECT, single-photon emission computerized tomography.
\end{abstract}

\section{Competing interests}

$\mathrm{RB}$ is co-founder and Chief Scientific Officer of Bioscape Imaging Solutions Inc. AMB received consultation fees from industry, including Pfizer and Lundbeck Canada. PR-N has ongoing scientific collaborations with NAVIDEA biopharmaceuticals (nonfinancial competing interests). The remaining authors declare that they have no competing interests.

\section{Acknowledgements}

RB would like to acknowledge the Ivey-BMO Financial Group Scientist in Brain Disorders Imaging Award. PR-N acknowledges support from the Le Fonds de recherche du Québec - Santé (FRQS) chercheurs-boursiers program, Canadian Institutes of Health Research, Alzheimer's Association and Aisenstadt Foundation.

\section{Declarations}

This article has been published as part of Alzheimer's Research \& Therapy Volume 5 Supplement 1, 2013: Background documents to the 4th Canadian Consensus Conference on the Diagnosis and Treatment of Dementia (CCCDTD4). The full contents of the supplement are available online at http://alzres.com/supplements/5/S1.

Publication charges for the supplement were funded by the Canadian Consensus Conference on the Diagnosis and Treatment of Dementia (CCCDTD). Although residual conference funds used include contributions from pharmaceutical companies, no commercial organization has been involved in the selection of participants, choice of topics, preparation of background papers or recommendations. In kind support was also provided by the Canadian Dementia Knowledge Translation Network, and the offices of Drs Serge Gauthier (McGill University), Christopher Patterson (McMaster University) and Howard Chertkow (McGill University), whose role as Guest Editors involved the coordination of the project without involvement in the journal's standard peer review process which applied for all articles.

\section{Author details}

'St Joseph's Health Care - London, University of Western Ontario, 850 Highbury Street North, PO Box 5532, Station B, London, Ontario, Canada 
N6A 1 H4. Imaging Research Group, Department of Medical Biophysics, Robarts Research Institute, University of Western Ontario, 100 Perth Drive, London, Ontario, Canada. ${ }^{3}$ Service de Neurologie, Département de Médecine, Faculté de Médecine et des Sciences de la Santé, Université de Sherbrooke, 3001-12e Avenue Nord, Sherbrooke, Québec, Canada. ${ }^{4}$ St Joseph's Health Care, Parkwood Hospital, Room A-280, 801 Commissioners Road East, London, Ontario, Canada. ${ }^{5} \mathrm{Clinique}$ Interdisciplinaire de Mémoire, Département des Sciences Neurologiques, CHU de Université Laval, 2325 rue de I'Université, Québec, Québec, Canada. ${ }^{6}$ Translational Neuroimaging Laboratory, Douglas Institute, FBC Pavilion, Room F-0105, 6875 boulevard LaSalle, Montreal, Québec, Canada. PPET Unit, McConnell Brain Imaging Centre, Montreal Neurological Institute, 3801 University Street, Montreal, Québec, Canada.

\section{Published: 8 July 2013}

\section{References}

1. Filippi M, Agosta F, Barkhof F, Dubois B, Fox NC, Frisoni GB, Jack CR, Johannsen P, Miller B, Nestor PJ, Scheltens P, Sorbi S, Teipel S, Thompson PM, Wahlund $\mathrm{L}-\mathrm{O}$ : EFNS task force: the use of neuroimaging in the diagnosis of dementia. Eur J Neurol 2012, 19:1487-1501. PMID:22900895

2. Oxford Centre of Evidence Based Medicine [http://www.cebm.net]

3. Stern Y: Cognitive reserve in ageing and Alzheimer's disease. Lancet Neurol 2012, 11:1006-1012. PMID:23079557

4. Chow T: Structural neuroimaging in the diagnosis of dementia. Alzheimers Dement 2007, 3:333-335. PMID:19595954

5. Borrie M: Functional neuroimaging in the diagnosis of dementia. Alzheimers Dement 2007, 3:336-340. PMID:19595955

6. Logothetis NK, Pauls J, Augath M, Trinath T, Oeltermann A: Neurophysiological investigation of the basis of the fMRI signal. Nature 2001, 412:150-157. PMID:11449264

7. Malonek D, Grinvald A: Interactions between electrical activity and cortical microcirculation revealed by imaging spectroscopy: implications for functional brain mapping. Science 1996, 272:551-554. PMID:8614805

8. Miller SL, Celone K, DePeau K, Diamond E, Dickerson BC, Rentz D, Pihlajamäki $M$, Sperling RA: Age-related memory impairment associated with loss of parietal deactivation but preserved hippocampal activation. Proc Natl Acad SciU S A 2008, 105:2181-2186. PMID:18238903

9. Machulda MM, Ward HA, Borowski B, Gunter $J \mathrm{~L}, \mathrm{Cha}$ RH, O'Brien PC, Petersen RC, Boeve BF, Knopman D, Tang-Wai DF, Ivnik RJ, Smith GE, Tangalos EG, Jack $\mathrm{CR} \mathrm{Jr}$ : Comparison of memory fMRI response among normal, $\mathrm{MCl}$, and Alzheimer's patients. Neurology 2003, 61:500-506. PMID:12939424

10. Golby A, Silverberg G, Race E, Gabrieli S, O'Shea J, Knierim K, Stebbins G, Gabrieli J: Memory encoding in Alzheimer's disease: an fMRI study of explicit and implicit memory. Brain 2005, 128:773-787. PMID:15705615

11. Sperling RA, Bates JF, Chua EF, Cocchiarella AJ, Rentz DM, Rosen BR, Schacter $D L$, Albert MS: fMRI studies of associative encoding in young and elderly controls and mild Alzheimer's disease. J Neurol Neurosurg Psychiatry 2003, 74:44-50. PMID:12486265

12. Miettinen $P S$, Pihlajamäki $M$, Jauhiainen $A M$, Niskanen $E_{\text {, }}$ Hänninen $T$, Vanninen R, Soininen $H$ : Structure and function of medial temporal and posteromedial cortices in early Alzheimer's disease. Eur J Neurosci 2011, 34:320-330. PMID:21692882

13. Lustig C, Snyder AZ, Bhakta M, O'Brien KC, MCAvoy M, Raichle ME, Morris JC, Buckner RL: Functional deactivations: change with age and dementia of the Alzheimer type. Proc Natl Acad Sci U S A 2003, 100:14504-14509. PMID:14608034

14. Solé-Padullés C, Bartrés-Faz D, Junqué C, Vendrell P, Rami L, Clemente IC, Bosch B, Villar A, Bargalló N, Jurado MA, Barrios M, Molinuevo JL: Brain structure and function related to cognitive reserve variables in normal aging, mild cognitive impairment and Alzheimer's disease. Neurobiol Aging 2009, 30:1114-1124. PMID:18053618

15. Grady CL, McIntosh AR, Beig S, Keightley ML, Burian H, Black SE: Evidence from functional neuroimaging of a compensatory prefrontal network in Alzheimer's disease. J Neurosci 2003, 23:986-993. PMID:12574428

16. Johnson SC, Schmitz TW, Moritz CH, Meyerand ME, Rowley HA, Alexander AL, Hansen KW, Gleason CE, Carlsson CM, Ries ML, Asthana S, Chen K, Reiman EM, Alexander GE: Activation of brain regions vulnerable to Alzheimer's disease: the effect of mild cognitive impairment. Neurobiol Aging 2006, 27:1604-1612. PMID:16226349

17. Petrella JR, Krishnan S, Slavin MJ, Tran TT, Murty L, Doraiswamy PM: Mild cognitive impairment: evaluation with 4-T functional MR imaging.
Radiology 2006, 240:177-186. PMID:16684919

18. Dickerson BC, Sperling RA: Functional abnormalities of the medial temporal lobe memory system in mild cognitive impairment and Alzheimer's disease: insights from functional MRI studies. Neuropsychologia 2008, 46:1624-1635. PMID:18206188

19. Miller SL, Fenstermacher E, Bates J, Blacker D, Sperling RA, Dickerson BC: Hippocampal activation in adults with mild cognitive impairment predicts subsequent cognitive decline. J Neurol Neurosurg Psychiatry 2008, 79:630635. PMID:17846109

20. O'Brien JL, O'Keefe KM, LaViolette PS, DeLuca AN, Blacker D, Dickerson BC, Sperling RA: Longitudinal fMRI in elderly reveals loss of hippocampal activation with clinical decline. Neurology 2010, 74:1969-1976. PMID:20463288

21. Schwindt GC, Black SE: Functional imaging studies of episodic memory in Alzheimer's disease: a quantitative meta-analysis. Neurolmage 2009, 45:181-190. PMID:19103293

22. Ries ML, Carlsson CM, Rowley HA, Sager MA, Gleason CE, Asthana S, Johnson SC: Magnetic resonance imaging characterization of brain structure and function in mild cognitive impairment: a review. J Am Geriatr Soc 2008, 56:920-934. PMID:18410325

23. Dickerson BC, Sperling RA: Large-scale functional brain network abnormalities in Alzheimer's disease: insights from functional neuroimaging. Behav Neurol 2009, 21:63-75. PMID:19847046

24. Biswal B, Yetkin FZ, Haughton VM, Hyde JS: Functional connectivity in the motor cortex of resting human brain using echo-planar MRI. Magn Reson Med 1995, 34:537-541. PMID:8524021

25. Fleisher AS, Sherzai A, Taylor C, Langbaum JB, Chen K, Buxton RB: Restingstate BOLD networks versus task-associated functional MRI for distinguishing Alzheimer's disease risk groups. Neuroimage 2009, 47:16781690. PMID:19539034

26. Rombouts SA, Barkhof F, Goekoop R, Stam CJ, Scheltens P: Altered resting state networks in mild cognitive impairment and mild Alzheimer's disease: an fMRI study. Hum Brain Mapp 2005, 26:231-239. PMID:15954139

27. Gili T, Cercignani M, Serra L, Perri R, Giove F, Maraviglia B, Caltagirone C, Bozzali M: Regional brain atrophy and functional disconnection across Alzheimer's disease evolution. J Neurol Neurosurg Psychiatry 2011, 82:58-66. PMID:20639384

28. Wang Z, Yan C, Zhao C, Qi Z, Zhou W, Lu J, He Y, Li K: Spatial patterns of intrinsic brain activity in mild cognitive impairment and Alzheimer's disease: a resting-state functional MRI study. Hum Brain Mapp 2011, 32:1720-1740. PMID:21077137

29. Hafkemeijer A, van der Grond J, Rombouts SA: Imaging the default mode network in aging and dementia. Biochim Biophys Acta 2012, 1822:431-441. PMID:21807094

30. Venneri A: Imaging treatment effects in Alzheimer's disease. Magn Reson Imaging 2007, 25:953-968. PMID:17446028

31. Li W, Antuono PG, Xie C, Chen G, Jones JL, Ward BD, Franczak MB, Goveas JS, $\mathrm{Li} \mathrm{SJ}$ : Changes in regional cerebral blood flow and functional connectivity in the cholinergic pathway associated with cognitive performance in subjects with mild Alzheimer's disease after 12-week donepezil treatment. Neurolmage 2012, 60:1083-1091. PMID:22245641

32. Trachtenberg AJ, Filippini N, Mackay CE: The effects of APOE-epsilon4 on the BOLD response. Neurobiol Aging 2012, 33:323-334. PMID:20409610

33. Trachtenberg AJ, Filippini N, Ebmeier KP, Smith SM, Karpe F, Mackay CE: The effects of APOE on the functional architecture of the resting brain. Neurolmage 2012, 59:565-572. PMID:21851856

34. Galvin JE, Price JL, Yan Z, Morris JC, Sheline YI: Resting bold fMRI differentiates dementia with Lewy bodies vs Alzheimer disease. Neurology 2011, 76:1797-1803. PMID:21525427

35. Sauer J, ffytche DH, Ballard C, Brown RG, Howard R: Differences between Alzheimer's disease and dementia with Lewy bodies: an fMRI study of task-related brain activity. Brain 2006, 129:1780-1788. PMID:16670180

36. Li C, Zheng J, Wang J, Gui L: Comparison between Alzheimer's disease and subcortical vascular dementia: attentional cortex study in functional magnetic resonance imaging. J Int Med Res 2011, 39:1413-1419. PMID 21986142

37. Rombouts SA, van Swieten JC, Pijnenburg YA, Goekoop R, Barkhof F, Scheltens $P$ : Loss of frontal fMRI activation in early frontotemporal dementia compared to early AD. Neurology 2003, 60:1904-1908. PMID:12821731

38. Sperling R: Potential of functional MRI as a biomarker in early Alzheimer's 
disease. Neurobiol Aging 2011, 32(Suppl 1):S37-S43. PMID:22078171

39. Clement $F$, Belleville $S$ : Test-retest reliability of $\mathrm{AMRI}$ verbal episodic memory paradigms in healthy older adults and in persons with mild cognitive impairment. Hum Brain Mapp 2009, 30:4033-4047. PMID:19492301

40. Bartha R, Drost DJ, Williamson PC: Factors affecting the quantification of short echo in-vivo 1 H MR spectra: prior knowledge, peak elimination, and filtering. NMR Biomed 1999, 12:205-216. PMID:10421912

41. Rapoport SI: Hydrogen magnetic resonance spectroscopy in Alzheimer's disease. Lancet Neurol 2002, 1:82. PMID:12849509

42. Loos C, Achten E, Santens P: Proton magnetic resonance spectroscopy in Alzheimer's disease, a review. Acta Neurol Belg 2010, 110:291-298. PMID:21305856

43. Kantarci K: $1 \mathrm{H}$ magnetic resonance spectroscopy in dementia. Br J Radiol 2007, 80(Spec No 2):S146-S152. PMID:18445744

44. Lehericy S, Marjanska M, Mesrob L, Sarazin M, Kinkingnehun S: Magnetic resonance imaging of Alzheimer's disease. Eur Radiol 2007, 17:347-362. PMID:16865367

45. Modrego PJ: Predictors of conversion to dementia of probable Alzheimer type in patients with mild cognitive impairment. Curr Alzheimer Res 2006, 3:161-170. PMID:16611017

46. Jones RS, Waldman AD: $1 \mathrm{H}-\mathrm{MRS}$ evaluation of metabolism in Alzheimer's disease and vascular dementia. Neurol Res 2004, 26:488-495. PMID:15265265

47. Valenzuela MJ, Sachdev P: Magnetic resonance spectroscopy in AD. Neurology 2001, 56:592-598. PMID:1 1261442

48. Griffith HR, Stewart CC, den Hollander JA: Proton magnetic resonance spectroscopy in dementias and mild cognitive impairment. Int Rev Neurobiol 2009, 84:105-131. PMID:19501715

49. Fayed N, Modrego PJ, Salinas GR, Gazulla J: Magnetic resonance imaging based clinical research in Alzheimer's disease. J Alzheimers Dis 2012, 31(Suppl 3):S5-S18. PMID:22233763

50. Siger M, Schuff N, Zhu X, Miller BL, Weiner MW: Regional myo-inositol concentration in mild cognitive impairment using $1 \mathrm{H}$ magnetic resonance spectroscopic imaging. Alzheimer Dis Assoc Disord 2009, 23:57-62. PMID:18725861

51. Griffith HR, den Hollander JA, Stewart CC, Evanochko WT, Buchthal SD, Harrell LE, Zamrini EY, Brockington JC, Marson DC: Elevated brain scyllo-inositol concentrations in patients with Alzheimer's disease. NMR Biomed 2007. 20:709-716. PMID:17295394

52. Rupsingh R, Borrie M, Smith M, Wells JL, Bartha R: Reduced hippocampal glutamate in Alzheimer disease. Neurobiol Aging 2011, 32:802-810. PMID:19501936

53. Moats RA, Ernst T, ShonkTK, Ross BD: Abnormal cerebral metabolite concentrations in patients with probable Alzheimer disease. Magn Reson Med 1994, 32:1 10-115. PMID:8084225

54. Kantarci K, Jack CR Jr, Xu YC, Campeau NG, O'Brien PC, Smith GE, Ivnik RJ, Boeve BF, Kokmen E, Tangalos EG, Petersen RC: Regional metabolic patterns in mild cognitive impairment and Alzheimer's disease: a 1H MRS study. Neurology 2000, 55:210-217. PMID:10908893

55. Miller BL, Moats RA, Shonk T, Ernst T, Woolley S, Ross BD: Alzheimer disease: depiction of increased cerebral myo-inositol with proton MR spectroscopy. Radiology 1993, 187:433-437. PMID:8475286

56. Deicken RF, Zhou L, Schuff N, Fein G, Weiner MW: Hippocampal neuronal dysfunction in schizophrenia as measured by proton magnetic resonance spectroscopy. Biol Psychiatry 1998, 43:483-488. PMID:9547926

57. Pouwels PJ, Frahm J: Regional metabolite concentrations in human brain as determined by quantitative localized proton MRS. Magn Reson Med 1998, 39:53-60. PMID:9438437

58. Bates TE, Strangward M, Keelan J, Davey GP, Munro PM, Clark JB: Inhibition of $\mathrm{N}$-acetylaspartate production: implications for $1 \mathrm{H}$ MRS studies in vivo. Neuroreport 1996, 7:1397-1400. PMID:8856684

59. Jessen F, Block W, Träber F, Keller E, Flacke S, Lamerichs R, Schild HH, Heun R: Decrease of $\mathrm{N}$-acetylaspartate in the MTL correlates with cognitive decline of AD patients. Neurology 2001, 57:930-932. PMID:11552037

60. Rose SE, de Zubicaray GI, Wang D, Galloway GJ, Chalk JB, Eagle SC, Semple J, Doddrell DM: A $1 \mathrm{H}$ MRS study of probable Alzheimer's disease and normal aging: implications for longitudinal monitoring of dementia progression. Magn Reson Imaging 1999, 17:291-299. PMID:10215485

61. Parnetti L, Tarducci R, Presciutti O, Lowenthal DT, Pippi M, Palumbo B, Gobbi G, Pelliccioli GP, Senin U: Proton magnetic resonance spectroscopy can differentiate Alzheimer's disease from normal aging. Mech Ageing Dev 1997, 97:9-14. PMID:9223122
62. Modrego PJ, Fayed N, Pina MA: Conversion from mild cognitive impairment to probable Alzheimer's disease predicted by brain magnetic resonance spectroscopy. Am J Psychiatry 2005, 162:667-675. PMID:15800137

63. Metastasio A, Rinaldi P, Tarducci R, Mariani E, Feliziani FT, Cherubini A, Pelliccioli GP, Gobbi G, Senin U, Mecocci P: Conversion of MCI to dementia: role of proton magnetic resonance spectroscopy. Neurobiol Aging 2006, 27:926-932. PMID:15936850

64. Rami L, Gómez-Anson B, Sanchez-Valle R, Bosch B, Monte GC, Lladó A, Molinuevo JL: Longitudinal study of amnesic patients at high risk for Alzheimer's disease: clinical, neuropsychological and magnetic resonance spectroscopy features. Dement Geriatr Cogn Disord 2007, 24:402-410. PMID:17934274

65. Fayed N, Davila J, Oliveros A, Castillo J, Medrano JJ: Utility of different MR modalities in mild cognitive impairment and its use as a predictor of conversion to probable dementia. Acad Radiol 2008, 15:1089-1098. PMID:18692749

66. Kantarci K, Weigand SD, Przybelski SA, Shiung MM, Whitwell JL, Negash S, Knopman DS, Boeve BF, O'Brien PC, Petersen RC, Jack CR Jr: Risk of dementia in MCl: combined effect of cerebrovascular disease, volumetric MRI, and 1H MRS. Neurology 2009, 72:1519-1525. PMID:19398707

67. Modrego PJ, Fayed N, Sarasa M: Magnetic resonance spectroscopy in the prediction of early conversion from amnestic mild cognitive impairment to dementia: a prospective cohort study. BMJ Open 2011, 1:e000007. PMID:22021723

68. Kantarci K, Weigand SD, Petersen RC, Boeve BF, Knopman DS, Gunter J, Reyes D, Shiung M, O'Brien PC, Smith GE, Ivnik RJ, Tangalos EG, Jack CR Jr: Longitudinal $1 \mathrm{H}$ MRS changes in mild cognitive impairment and Alzheimer's disease. Neurobiol Aging 2007, 28:1330-1339. PMID:16860440

69. Pilatus U, Lais C, Rochmont Adu M, Kratzsch T, Frölich L, Maurer K, Zanella FE, Lanfermann $\mathrm{H}$, Pantel J: Conversion to dementia in mild cognitive impairment is associated with decline of $\mathrm{N}$-actylaspartate and creatine as revealed by magnetic resonance spectroscopy. Psychiatry Res 2009, 173:1-7. PMID:19427767

70. Chao LL, Schuff N, Kramer JH, Du AT, Capizzano AA, O'Neill J, Wolkowitz OM, Jagust WJ, Chui HC, Miller BL, Yaffe K, Weiner MW:Reduced medial temporal lobe $\mathrm{N}$-acetylaspartate in cognitively impaired but nondemented patients. Neurology 2005, 64:282-289. PMID:15668426

71. Dubois B, Feldman HH, Jacova C, Dekosky ST, Barberger-Gateau P, Cummings J, Delacourte A, Galasko D, Gauthier S, Jicha G, Meguro K, O'Brien J, Pasquier F, Robert P, Rossor M, Salloway S, Stern Y, Visser PJ, Scheltens P: Research criteria for the diagnosis of Alzheimer's disease: revising the NINCDS-ADRDA criteria. Lancet Neurol 2007 6:734-746. PMID:17616482

72. Le Bihan D, Johansen-Berg H: Diffusion MRI at 25: exploring brain tissue structure and function. Neurolmage 2012, 61:324-341. PMID:22120012

73. Assaf Y, Pasternak O: Diffusion tensor imaging (DTI)-based white matter mapping in brain research: a review. J Mol Neurosci 2008, 34:51-61. PMID:18157658

74. Mesulam MM: Large-scale neurocognitive networks and distributed processing for attention, language, and memory. Ann Neurol 1990, 28:597613. PMID:2260847

75. Jeurissen B, Leemans A, Tournier JD, Jones DK, Sijbers J: Investigating the prevalence of complex fiber configurations in white matter tissue with diffusion magnetic resonance imaging. Hum Brain Mapp 2012. doi: $101002 /$ hbm22099. PMID:22611035

76. Descoteaux M, Deriche R, Knosche TR, Anwander A: Deterministic and probabilistic tractography based on complex fibre orientation distributions. IEEE Trans Med Imaging 2009, 28:269-286. PMID:19188114

77. Tournier JD, Mori S, Leemans A: Diffusion tensor imaging and beyond. Magn Reson Med 2011, 65:1532-1556. PMID:21469191

78. Clerx L, Visser PJ, Verhey F, Aalten P: New MRI markers for Alzheimer's disease: a meta-analysis of diffusion tensor imaging and a comparison with medial temporal lobe measurements. J Alzheimers Dis 2012, 29:405429. PMID:22330833

79. Sexton CE, Kalu UG, Filippini N, Mackay CE, Ebmeier KP: A meta-analysis of diffusion tensor imaging in mild cognitive impairment and Alzheimer's disease. Neurobiol Aging 2011, 32:2322.e5-e18. PMID:20619504

80. Bendlin BB, Ries ML, Canu E, Sodhi A, Lazar M, Alexander AL, Carlsson CM, Sager MA, Asthana S, Johnson SC: White matter is altered with parental family history of Alzheimer's disease. Alzheimers Dement 2010, 6:394-403. PMID:20713315

81. Gold BT, Johnson NF, Powell DK, Smith CD: White matter integrity and 
vulnerability to Alzheimer's disease: preliminary findings and future directions. Biochim Biophys Acta 2012, 1822:416-422. PMID:21803153

82. Grambaite R, Reinvang I, Selnes P, Fjell AM, Walhovd KB, Stenset V, Fladby T: Pre-dementia memory impairment is associated with white matter tract affection. J Int Neuropsychol Soc 2011, 17:143-153. PMID:21092388

83. Bozoki AC, Korolev IO, Davis NC, Hoisington LA, Berger KL: Disruption of limbic white matter pathways in mild cognitive impairment and Alzheimer's disease: a DTI/FDG-PET study. Hum Brain Mapp 2012, 33:17921802. PMID:21674695

84. Wang PN, Chou KH, Lirng JF, Lin KN, Chen WT, Lin CP: Multiple diffusivities define white matter degeneration in amnestic mild cognitive impairment and Alzheimer's disease. J Alzheimers Dis 2012, 30:423-437. PMID:22430530

85. Douaud G, Jbabdi S, Behrens TE, Menke RA, Gass A, Monsch AU, Rao A, Whitcher B, Kindlmann G, Matthews PM, Smith S: DTI measures in crossingfibre areas: increased diffusion anisotropy reveals early white matter alteration in MCl and mild Alzheimer's disease. Neuroimage 2011, 55:880890. PMID:21182970

86. Raffelt D, Tournier JD, Rose S, Ridgway GR, Henderson R, Crozier S, Salvado O, Connelly A: Apparent fibre density: a novel measure for the analysis of diffusion-weighted magnetic resonance images. Neuroimage 2012, 59:3976-3994. PMID:22036682

87. Bosch B, Arenaza-Urquijo EM, Rami L, Sala-Llonch R, Junqué C, Solé-Padullés C, Peña-Gómez C, Bargalló N, Molinuevo JL, Bartrés-Faz D: Multiple DTI index analysis in normal aging, amnestic $\mathrm{MCl}$ and $\mathrm{AD}$. Relationship with neuropsychological performance. Neurobiol Aging 2012, 33:61-74. PMID:20371138

88. Ciccarelli O, Catani M, Johansen-Berg H, Clark C, Thompson A: Diffusionbased tractography in neurological disorders: concepts, applications, and future developments. Lancet Neurol 2008, 7:715-727. PMID:18635020

89. Cui Y, Wen W, Lipnicki DM, Beg MF, Jin JS, Luo S, Zhu W, Kochan NA, Reppermund S, Zhuang L, Raamana PR, Liu T, Trollor JN, Wang L, Brodaty H, Sachdev PS: Automated detection of amnestic mild cognitive impairment in community-dwelling elderly adults: a combined spatial atrophy and white matter alteration approach. Neurolmage 2012, 59:1209-1217. PMID:21864688

90. Oishi K, Akhter K, Mielke M, Ceritoglu C, Zhang J, Jiang H, Li X, Younes L, Miller MI, van Zijl PC, Albert M, Lyketsos CG, Mori S: Multi-modal MRI analysis with disease-specific spatial filtering: initial testing to predict mild cognitive impairment patients who convert to Alzheimer's disease. Front Neurol 2011, 2:54. PMID:21904533

91. Persson J, Lind J, Larsson A, Ingvar M, Cruts M, Van Broeckhoven C, Adolfsson R, Nilsson LG, Nyberg L: Altered brain white matter integrity in healthy carriers of the APOE epsilon4 allele: a risk for AD? Neurology 2006, 66:10291033. PMID:16606914

92. Cheng Y, Ono M, Kimura H, Ueda M, Saji H: Technetium-99m labeled pyridyl benzofuran derivatives as single photon emission computed tomography imaging probes for beta-amyloid plaques in Alzheimer's brains. J Med Chem 2012, 55:2279-2286. PMID:22364445

93. Fodero-Tavoletti MT, Okamura N, Furumoto S, Mulligan RS, Connor AR, McLean CA, Cao D, Rigopoulos A, Cartwright GA, O'Keefe G, Gong S, Adlard PA, Barnham KJ, Rowe CC, Masters CL, Kudo Y, Cappai R, Yanai K, Villemagne VL: 18F-THK523: a novel in vivo tau imaging ligand for Alzheimer's disease. Brain 2011, 134(Pt 4):1089-1100. PMID:21436112
94. Esposito G, Giovacchini G, Liow JS, Bhattacharjee AK, Greenstein D, Schapiro M, Hallett M, Herscovitch P, Eckelman WC, Carson RE, Rapoport SI: Imaging neuroinflammation in Alzheimer's disease with radiolabeled arachidonic acid and PET. J Nucl Med 2008, 49:1414-1421. PMID:18703605

95. Santillo AF, Gambini JP, Lannfelt L, Långström B, Ulla-Marja L, Kilander L, Engler H: In vivo imaging of astrocytosis in Alzheimer's disease: an (1)(1) C-L-deuteriodeprenyl and PIB PET study. Eur J Nucl Med Mol Imaging 2011, 38:2202-2208. PMID:21853308

96. Herholz K, Carter SF, Jones M: Positron emission tomography imaging in dementia. Br J Radiol 2007, 80(Spec No 2):S160-S167. PMID:18445746

97. Mori T, Maeda J, Shimada H, Higuchi M, Shinotoh H, Ueno S, Suhara T: Molecular imaging of dementia. Psychogeriatrics 2012, 12:106-114. PMID:22712644

98. Johnson NA, Jahng GH, Weiner MW, Miller BL, Chui HC, Jagust WJ, GornoTempini ML, Schuff N: Pattern of cerebral hypoperfusion in Alzheimer disease and mild cognitive impairment measured with arterial spinlabeling MR imaging: initial experience. Radiology 2005, 234:851-859. PMID:15734937

99. Alsop DC, Detre JA, Grossman M: Assessment of cerebral blood flow in Alzheimer's disease by spin-labeled magnetic resonance imaging. Ann Neurol 2000, 47:93-100. PMID:10632106

100. Cummings $J$ L, Henchcliffe C, Schaier S, Simuni T, Waxman A, Kemp P: The role of dopaminergic imaging in patients with symptoms of dopaminergic system neurodegeneration. Brain 2011, 134(Pt 11):3146-3166. PMID:21810889

101. Hanyu H, Shimizu S, Hirao K, Kanetaka H, Iwamoto T, Chikamori T, Usui Y, Yamashina A, Koizumi K, Abe K: Comparative value of brain perfusion SPECT and [(123)I]MIBG myocardial scintigraphy in distinguishing between dementia with Lewy bodies and Alzheimer's disease. Eur J NuCl Med Mol Imaging 2006, 33:248-253. PMID:16328506

102. Suzuki M, Kurita A, Hashimoto M, Fukumitsu N, Abo M, Ito Y, Urashima M, Inoue K: Impaired myocardial ${ }^{123}$-metaiodobenzylguanidine uptake in Lewy body disease: comparison between dementia with Lewy bodies and Parkinson's disease. J Neurol Sci 2006, 240:15-19. PMID:16199056

103. Kerchner GA: Ultra-high field 7T MRI: a new tool for studying Alzheimer's disease. J Alzheimers Dis 2011, 26(Suppl 3):91-95. PMID:21971453

104. van der Kolk AG, Hendrikse J, Zwanenburg JJ, Visser F, Luijten PR: Clinical applications of 7T MRI in the brain. Eur J Radiol 2013, 82:708-718. PMID:21937178

105. Thomas BP, Welch EB, Niederhauser BD, Whetsell WO Jr, Anderson AW, Gore $J$ C, Avison MJ, Creasy JL: High-resolution 7T MRI of the human hippocampus in vivo. J Magn Reson Imaging 2008, 28:1266-1272. PMID:18972336

106. Carrillo MC, Bain $L$, Frisoni GB, Weiner MW: Worldwide Alzheimer's disease neuroimaging initiative. Alzheimers Dement 2012, 8:337-342. PMID:22748939

doi:10.1186/alzrt200

Cite this article as: Burhan AM, et al.: Role of emerging neuroimaging modalities in patients with cognitive impairment: a review from the Canadian Consensus Conference on the Diagnosis and Treatment of Dementia 2012. Alzheimer's Research \& Therapy 2013, 5(Suppl 1):S4. 